\title{
JNPH
}

Volume 7 No. 1 (April 2019)

(C) The Author(s) 2019

\section{HUBUNGAN TINGKAT PENGETAHUAN DAN PENGGUNAAN ALAT PELINDUNG DIRI (APD) DENGAN KEJADIAN GANGGUAN KESEHATAN PADA PETANI PENGGUNA PESTISIDA DI DESA SIMPANG PINO KECAMATAN ULU MANNA TAHUN 2018}

\author{
RELATIONSHIP OF KNOWLEDGE AND USE OF SELF PROTECTIVE EQUIPMENT \\ (APD) WITH THE EVENT OF HEALTH DISORDERS IN PESTICIDES USERS IN \\ SIMPANG PINO, SUB-DISTRICT ULU MANNA IN 2018
}

\author{
MELY GUSTINA, ULLYA RAHMAWATI, MUALIM, NANO SETIAWAN ZOLENDO \\ JURUSAN KESEHATAN LINGKUNGAN, POLTEKKES KEMENKES BENGKULU \\ Email : nanozolendo@gmail.com
}

\begin{abstract}
ABSTRAK
Para petani sering menggunakan pestisida bukan atas dasar keperluan pengendalian hama secaraindikatif,mereka melakukan penyemprotan tanaman tanpamemperhatikan ada tidaknya serangan hama,penggunaan semacam ini telah banyak menimbulkan masalah adanya kandungan residu pestisida pada produk pertanian dan pencemaran lingkungan,khususnya pencemaran udara yang dapat menyebabkan penyakit saluran pernapasan pada para petani.Indonesia sebagai salah satu negara di dunia,sangat berkepentingan terhadap masalah Kesehatan dan Keselamatan Kerja (K3. Penelitian ini bertujuan untuk mengetahui hubungan tingkat pengetahuan dan penggunaan APD dengan kejadian gangguan kesehatan pada petani penggunaan pestisida di Desa Simpang Pino Kecamatan Ulu Manna Tahun 2018. Jenis penelitian adalah Deskriptif dengan metode penelitian survey analitik dengan rancangan cross sectional, yaitu untuk menilai Hubungan pengetahuan dan penggunaan Alat Pelindung Diri (APD) dengan kejadian gangguan kesehatan pada petani pengguna Pestisida. Hasil penelitian 50 sampel pada petani pengguna pestisida di Desa Simpang Pino Kecamatan Ulu Manna Tahun bahwa lebih dari sebagian responden 31 (62\%) yang memiliki pengetahuan kurang, lebih dari sebagian responden 34 (68\%) yang menggunakan APD lengkap, dan lebih dari sebagian responden $29(58 \%)$ mengalamigangguan kesehatan sedang
\end{abstract}

Kata Kunci : Pengetahuan, Penggunaan APD, Gangguan Kesehatan

\begin{abstract}
Farmers often use pesticides not on the basis of predictive pest control needs, they spray plants without paying attention to the presence or absence of pest attacks, this kind of use has caused many problems with the presence of pesticide residues in agricultural products and environmental pollution, especially air pollution which can cause respiratory diseases Indonesian farmers as one of the countries in the world are very interested in Occupational Health and Safety (OHS). This study aims to determine the relationship between the level of knowledge and use of PPE with the occurrence of health problems in farmers using pesticides in Simpang Pino Village, Ulu Manna, Tahun 2018. This type of research is descriptive with
\end{abstract}


analytical survey research method with a cross sectional design, namely to assess the relationship of knowledge and use of personal protective equipment (PPE) to the incidence of health problems in farmers using Pesticides. The results of 50 samples of farmers using pesticides in Simpang Pino Village, Ulu Manna Tahun District, that more than half of the respondents $31(62 \%)$ had insufficient knowledge, more than half of the respondents $34(68 \%)$ used complete PPE, and more than half of respondents $29(58 \%)$ experienced moderate health problems

\section{Keywords: Knowledge, Use of APD, Health Problems}

\section{PENDAHULUAN}

$\begin{array}{rcr}\text { Para } & \text { petani sering menggunakan } \\ \text { pestisida } & \text { bukan } & \text { atas dasar }\end{array}$ keperluan pengendalian hama secara indikatif, mereka melakukan penyemprotan tanaman tanpa memperhatikan ada tidaknya serangan hama, penggunaan semacam ini telah banyak menimbulkan masalah adanya kandungan residu pestisida pada produk pertanian dan pencemaran lingkungan, khususnya pencemaran udara yang dapat menyebabkan penyakit saluran pernapasan pada para petani. Indonesia sebagai salah satu negara di dunia, sangat berkepentingan terhadap masalah Kesehatan dan Keselamatan Kerja (K3). Hal ini disebabkan karena dapat menimbulkan berbagai dampak positif dan dampak negatif. Salah satu dampak negatif adalah meningkatnya Penyakit Akibat Kerja (PAK). Dengan program K3 diharapkan dapat mengurangi atau bebas dari kecelakaan dan penyakit akibat kerja yang akan dapat meningkatkan efisiensi dan produktivitas kerja. Karena tercipta lingkungan kerja yang aman, sehat dan bebas dari pencemaran lingkungan (Tresnaniangsih, 2015).

World Health Organisasion (WHO) memperkirakan setiap tahun terjadi 1-5 juta kasus keracunan pestisida pada pekerja pertanian yang sebagian besar $(80 \%)$ terjadi di Negara-negara berkembang. Data WHO menunjukan bahwa dampak yang ditimbulkan akibat keracunan pestisida dapat sangat fatal seperti kanker, cacat, kemandulan dan gangguan hepar.

Berdasarkan informasi yang diperoleh dari petugas penyuluh pertanian pada wilayah kerja Kecamatan Ulu Manna Kabupaten
Bengkulu Selatan dan data dari kepala Desa Simpang Pino, serta survey awal yang peneliti lakukan pada tangal 2 Desember 2017, jumlah petani yang ada di Desa Simpang Pino Dengan petani pengguna pestisida berjumlah 50 orang dan penyuluhan baru satu kali dilakukan dari dinas pertanian.

Survei awal peneliti pada hari Sabtu 2 Desember 2017, pada petani pengguna Pestisida di Desa Simpang Pino sejumlah 18 orang ditemukan $67 \%$ orang pengetahuannya kurang dan ditemukan $44 \%$ orang mengalami gangguan kesehatan yaitu $62,5 \%$ orang mengeluh pusing, $25 \%$ orang mual-mual dan $12,5 \%$ merasa keringat berlebihan. Dari 18 orang petani pengguna pestisida tersebut yang memakai Alat Pelindung Diri sebanyak 17\% orang dan yang tidak memakai Alat Pelindung Diri $83 \%$ orang. Pemakaian alat pelindung diri yang kurang lengkap dapat memungkinkan kontak langsung dengan pestisida sehingga mengakibatkan terjadinya gangguan kesehatan. Oleh karena itu, penulis merasa tertarik untuk melakukan penelitian pada petani di Desa Simpang Pino Kecamatan Ulu Manna Kabupaten Bengkulu Selatan untuk mengetahui sejauh mana hubungan tingkat pengetahuan dan penggunaan APD dengan kejadian gangguan kesehatan pada petani pengguna pestisida di Desa Simpang Pino kecamatan.Ulu Manna tahun 2018.

\section{METODE PENELITIAN}

Jenis penelitian adalah Deskriptif dengan metode penelitian survey analitik dengan rancangan cross sectional, yaitu untuk menilai Hubungan pengetahuan dan 
penggunaan Alat Pelindung Diri (APD) dengan kejadian gangguan kesehatan pada petani pengguna Pestisida

\section{HASIL}

Hasil penelitian ini menunjukkan bahwa ada responden pengetahuan baik dan mengalami gangguan ringan sebanyak 13 $(68,4 \%)$, hal ini karena responden cukup mengetahui bahaya penggunaan pestisida terhadap gangguan kesehatan. Sedangkan ada responden yang pengetahuan kurang dan mengalami gangguan kesehatan sedang 23 (74,2\%), hal ini karena responden kurangnya mengetahui tentang bahaya dan akibat dari penggunaan pestisida tersebut.

Berdasarkan uji statistik Chi-square diperoleh nilai kemaknaan $p=0,008$ ( $p<$ $0,05)$ berarti Ha di terima dan Ho di tolak dan ada hubungan yang bermakana pengetahuan dengan gangguan kesehatan pada petani pengguna pestisida di Desa Simpang Pino Kecamatan Ulu Manna Tahun 2018. Dan Odd Ratio yang diperoleh dari uji statistik diperoleh nilai $\mathrm{OR}=6,229$ berarti petani pengguna pestisida yang memiliki pengetahuan kurang 6 kali lebih berisiko mengalami gangguan kesehatan. Hasil penelitian ini sejalan dengan hasil penelitian bihir 2013. Berdasarkan uji statistik Chisquare diperoleh nilai kemaknaan $p=0,001$ $(p<0,05)$ berarti Ha di terima dan Ho di tolak dan ada hubungan yang bermakana pengetahuan dengan stress kerja pada pekerja mebel di desa mojok kecamatan suka karya tahun 2013.

Pengetahuan (knowledge) adalah merupakan hasil "tahu" dan ini terjadi setelah melakukan penginderaan terhadap suatu objek tertentu. Pengideraan terjadi melalui panca indera manusia, yakni penglihatan, pendengaran, penciuman, rasa dan raba. Sebagian besar pengetahuan manusia diperoleh dari mata dan telinga, pengetahuan merupakan dari bagian perilaku yang tidak bisa diamati secara langsung oleh orang lain karna masih terjadi didalam diri manusia itu sendiri (Notoatmodjo, 2007).
Pengetahuan petani di Desa Simpang Pino Kecamatan Ulu Manna termasuk dalam katagori kurang baik dan mengalami gangguan kesehatan sedang. Hubungan pengetahuan dengan gangguan kesehatan adalah jika pengetahuan petani baik dan petani mengetahui bahaya dan cara penggunaan pestisida maka kejadian gangguan kesehatan akan mengurang yang pada akhirnya petani akan mengurangi resiko terjadinya gangguan kesehatan akibat penggunaan pestisida. Dengan pengetahuan yang luas pestisida dan bahaya, para petani akan bertingkah laku baik sehingga terhindar bahaya yang diakibatakn oleh pestisia. Pengetahuan tentang penggunaan pestisida secara aman pada pertanian, akan bermanfaat bagi orang yang menggunakan pestisida itu sendiri, masyarakat luas dan lingkungan secara umum (Suhenda, 2009).

\section{PEMBAHASAN}

Hasil penelitian menunjukkan dari 34 responden yang memakai APD lengkap dan mengalami gangguan kesehatan ringan sebanyak $(55,9 \%)$, sedangkan responden yang menggunakan APD lengkap dan mengalami gangguan kesehatan sedang (44,1\%). Dari 16 responden yang menggunakan APD tidak lengkap dan mengalami gangguan kesehatan ringan hanya $(12,5 \%)$, sedangkan dari tabel diatas menunjukkan bahwa sebagian besar responden (87,5\%) menggunakan APD tidak lengkap dan mengalami gangguan kesehatan sedang.

Hasil penelitian ini menunjukkan bahwa ada responden yang menggunakan APD tidak lengkap dan mengalami gangguan kesehatan sedang sebanyak $(87,5 \%)$, hal ini karena kurangnya ketersediaan dan kesadaran petani menggunakan APD. Sedangkan ada responden menggunakan APD lengkap dan mengalami gangguan kesehatan ringan sebanyak $(55,9 \%)$, hal ini karena responden meniru responden yang lain untuk menggunakan APD. Berdasarkan uji statistik Chi-square diperoleh nilai kemaknaan $p=$ $0,004(p=<0,05)$ yang berarti Ha di terima 
dan Ho di tolak dan ada hubungan yang bermakna antara penggunaan APD dengan gangguan kesehatan pada petani pengguna pestisida di Desa Simpang Pino Kecamatan Ulu Manna Tahun 2018. Dan Odd Ratio yang diperoleh dari uji statistik diperoleh nilai OR $=8,867$ berarti petani pengguna pestisida yang menggunakan APD tidak lengkap 9 kali lebih berisiko mengalami gangguan kesehatan. Hasil penelitian ini sejalan dengan hasil penelitian burlan 2011. Berdasarkan uji statistik Chi-square diperoleh nilai kemaknaan $p=0,002(p<0,05)$ berarti Ha di terima dan Ho di tolak dan ada hubungan yang bermakana penggunaan APD dengan gangguan kesehatan pada petani cabe di desa tj.aur kecamatan lankap tahun 2015. Penelitian ini sejalan dengan teori afrianto (2009) yaitu:

Semua pestisida mempunyai bahaya potensial bagi kesehatan. Ada dua tipe keracunan, yaitu keracunan langsung dan jangka panjang. Keracunan akut terjadi bila efek-efek keracunan pestisida dirasakan langsung pada saat itu. Keracunan kronis terjadi bila efek-efek keracunan pada kesehatan membutuhkan waktu untuk muncul atau berkembang. Efek-efek jangka panjang ini dapat muncul setelah berbulanbulan atau bahkan bertahun - tahun setelah terkena pestisida. Beberapa efek-efek kesehatan akut adalah: Pusing, Sakit kepala, Mual, Kudis, Muntah-muntah , Sakit dada, Kram, Sulit bernafas, Pengelihatan Kabur, Diare, Keringat berlebihan, dan Kematian (Afriyanto, 2009).

\section{KESIMPULAN}

Berdasarkan hasil penelitian dan pembahasan, maka dapat disimpulkan sebagai berikut :

1. Lebih dari sebagian 31 (62\%) responden memiliki pengetahuan kurang, Lebih dari sebagian $34 \quad(68 \%)$ responden menggunakan APD lengkap dan Lebih dari sebagian $29 \quad(58 \%)$ responden mengalami gangguan kesehatan sedang.
2. Ada hubungan yang bermakna antara Pengetahuan dengan kejadian Gangguan Kesehatan pada petani pengguna pestisida di Desa Simpang Pino Kecamatan Ulu Manna Tahun 2018. Dengan nilai kemaknaan $p=0,008(p<0,05)$.

3. Ada hubungan yang bermakna antara penggunaan Alat Pelindung Diri (APD) dengan kejadian Gangguan Kesehatan pada petani pengguna pestisida di Desa Simpang Pino Kecamatan Ulu Manna Tahun 2018. Dengan nilai kemaknaan $p=$ $0,004(p=<0,05)$.

\section{SARAN}

1. Bagi Akademik

Diharap intansi pendidikan yaitu Poltekkes Kemenkes Bengkulu Jurusan Kesehatan Lingkungan dalam kegiatan lapangan agar dianjurkan menyampaikan hal-hal yang berhubungan dengan pemakaian APD pada petani pengguna pestisida. Selain itu juga diharapkan pihak pendidikan bekerjasama dengan pihak puskesmas dan penyuluhan pertanian agar mahasiswa dapat memberikan penyuluhan tentang alat pelindung diri pada petani pengguna pestisida.

2. Bagi petani/responden

Disarankan agar dapat lebih memahami pentingnya keselamatan secara mandiri, dan membaca terlebih dahulu yang tertera pada label kemasan mau botolan pestisida lalu menerapkanya serta memahami arti pentingnya penggunaan alat pelindung diri saat menggunakan pestisida tersebut.

3. Bagi Peneliti Selanjutnya

Bagi peneliti selanjutnya dapat mengembangkan penelitian ini dengan metode-metode lain misalnya faktor yang berkaitan yang dapat mempengaruhi pemakaian APD pada petani pengguna pestisida. 


\section{DAFTAR PUSTAKA}

Afriayanto, 2009. Kajian Keracunan Pestisida Pada Petani Penyemprot Cabe Di Desa Candi Kecamatan Bandung Kabupaten Semarang. Tesis. Semarang: Program Pascasajana Kesehatan Lingkungan: UNDIP.2009.http;//eprints.undip.ac.id/16 405/AFRYANTO.pdf. Diakses Tanggal 13 Desember 2017 Jam 21,05 WIB.

Direktorat Jendral Prasarana dan Sarana Direktorat Pupuk dan Pestisida Kementerian Pertanian 2012, Pedoman Teknik Kajian Pestisida Terdaftar Beredar TA 2012.

Erlan, 2010. Pengaruh Pestisida Dalam Lingkungan Pertanian: http://repository.usu.ac.id. Betstream / 123456789/11 06/3/fp. diana.pdf.txt, Di Akses Tanggal 23 Desember 2017.

Eric R. Wolf , 2010. "Moral Ekonomi Petani'Jakarta:Rieneka Cipta

Himmawan, L., 2012. Pengaruh Pemakain Alat Pelindung Pernapasan Terhadap Kapasitas Fungsi Paru Petani Sayuran Penggunaan Pestisida. Skripsi. Semarang : FIK UNNES.2012.

L., 2012. Metodologi Penelitian Kesehatan.Jakarta:Rieneka Cipta.

Irnawati Marsaulina, 2009, Faktor-faktor yang berhubungan dengan keracunan pestisida pada petani sayur di kota Jambi. Tesis UI

Kemenkes, RI., 2011. Profil Kesehatan Indonesia 2012. Jakarta.

Keputusan Menteri Kesehatan RI No : 1350/Menkes/Sk/Xii/2012, Tentang Pestisida.

RI No :434. 1/Kpts/TP. 270/7/2001, Tentang Syarat Dan Tata Cara Pendaftaran Pestisida.

Notoatmodjo, S, 2012. Metodologi Penelitian Kesehatan. Jakarta : Rieneka Cipta.

Sastraatmadja, 2010. Penyuluhan Pertanian, Bandung.

Suma'mur. 2006. Keselamatan Kerja dan Pencegahan Kecelakaan, PT. Gunung Agung. Jakarta

Sutomo, 2009. Studi Ekonomi Lingkungan
Penggunaan Pestisida dan Dampaknya pada Kesehatan Petani di Area Pertanian Hortikultura Desa Sumber Rejo Kecamatan Ngablak Kabupaten Magelang Jawa Tengah Tesis.Program Pasca Sarjana Universitas Dipenogoro Semarang 2009.

Trisnangsih, 2015. Pengaruh Pendidikan Kesehatan Tentang Penggunaan Masker Terhadap Pengetahuan Dan sikap Pekerja Pengaplasan Kayu Di Desa Rengging Pecangaan Jepara: Fakultas Ilmu Kesahatn, Universitas Muhammadiah Sukarta.

Wardhana, 2011. Alat Pelindung Diri (APD : http:// dianwisnuwardhana. Blogspot.Com/2011/10/alat-pelidungdiri-apd.html,) Diakses Tanggal 23 Desember 2017.

Weis et al. 2012. Kadar Residu Pestisida Golongan Organofosfat pada Beberapa Jenis Sayuran. Jurnal Santina 1: 520-525 